\title{
EFEITO DA SUPLEMENTAÇÃO DE GLUTAMINA SOBRE VARIÁVEIS HEMATOLÓGICAS E DO ESTADO NUTRICIONAL DE RATAS DESNUTRIDAS
}

\section{Glutamine supplementation effect in hematological parameters and nutritional status of rats submitted to malnutrition protocol}

\author{
Natália Cristina Lima RODRIGUES ${ }^{1}$, Lázaro Alessandro NUNES ${ }^{2}$, \\ Lilian M. HORIE ${ }^{2}$, R. TORRINHAS ${ }^{2}$, Dan L. WAITZBERG ${ }^{2}$
}

ABCDDV/573

Rodrigues NCL, Nunes LA, Horie LM, Torrinhas R, Waitzberg DL. Efeito da suplementação de glutamina sobre variáveis hematológicas e do estado nutricional de ratas desnutridas. ABCD Arq Bras Cir Dig 2007;20(4):270--3

RESUMO - Racional - A glutamina é o aminoácido mais abundante no sangue, por desempenhar importante papel no sistema imune. É considerado aminoácido condicionalmente essencial em situações como desnutrição protéico-calórica. Objetivo - Verificar o efeito da dieta suplementada com glutamina sobre variáveis bioquímicas e hematológicas de ratas submetidas a protocolo de desnutrição, induzido por dieta rica em lactose. Métodos - Ratas Wistar fêmeas $(\mathrm{n}=20)$ e com 21 dias de idade, foram submetidas ou não à desnutrição calórico-protéica induzida por diarréia, através da administração de dieta rica em lactose $60 \%$ durante 15 dias. Após o período de desnutrição, animais eutróficos ou desnutridos permaneceram durante 30 dias com oferta de diferentes dietas (padrão e experimentais). De acordo com estado e tratamento nutricionais, os animais foram distribuídos aleatoriamente em quatro grupos distintos: 1) GC: animais eutróficos + dieta padrão, 2) GD: animais desnutridos + dieta rica em lactose (60\%), 3) GDGLN: animais desnutridos + dieta rica em glutamina (2\%); e 4) GDP: animais desnutridos + dieta padrão. Após os 30 dias de tratamento nutricional, amostras de sangue foram obtidas por punção cardíaca para avaliação de variáveis bioquímicas (proteínas totais, albumina, uréia) e hematológicas (quantificação da série vermelha e branca). Resultados - Após 15 dias do início do experimento o ganho de peso dos grupos GD $(46,4 \pm 2,60 \mathrm{~g})$, GDGLN $(39,2 \pm 8,9 \mathrm{~g})$ e GDP $(33,2 \pm 11,5 \mathrm{~g})$ foi menor em relação ao controle $(64 \pm 4,24 \mathrm{~g}, \mathrm{P}<0,05)$. Nos exames bioquímicos observou-se diferença significativa apenas na dosagem de uréia no GD em relação aos demais grupos $(33,4 \pm 4,77 \mathrm{mg} / \mathrm{dL}, \mathrm{P}<0,05)$. A contagem de leucócitos do GD $(3,68 \pm 1,0$ x103 cel/mm3) mostrou-se diminuída em relação aos demais grupos $(\mathrm{P}<0,05)$ e a série vermelha não apresentou diferenças significativas. Conclusão - A desnutrição prejudica o número de leucócitos sanguíneos e esse efeito deletério é revertido pela simples re-nutrição, independente da suplementação com glutamina. A ingestão oral de glutamina não influencia o ganho de peso, variáveis bioquímicas de estado nutricional e número de leucócitos de animais desnutridos por ingestão de dieta rica em lactose.

DESCRITORES - Suplementação, nutrição. Glutamina. Desnutrição.

\section{INTRODUÇÃO}

Desnutrição protéico-calórica é definida pela Organização Mundial de Saúde como a condição patológica decorrente da baixa ingestão calórica. Ela ocorre mais freqüentemente em crianças com menos de cinco anos de idade e está freqüentemente associada à infecções ${ }^{1}$. A glutamina é aminoácido não essencial, sintetizado a partir das necessidades corporais. Dentre as funções que exerce no organismo, ela participa da manutenção do sistema imunológico; do controle do volume celular; da desintoxicação corporal do nitrogênio e da amônia e exerce possível ação reguladora da síntese e da degradação de proteínas ${ }^{4}$.

A desnutrição protéico-calórica, assim como estresse, injúrias e desgastes orgânicos aumentam a demanda de glutamina, de tal forma que sua síntese corporal não consegue suprir as necessidades desse aminoácido ${ }^{5}$. Por essa razão, é considerada um aminoácido condicionalmente essencial.

Trabalho realizado no Departamento de Gastroenterologia, Disciplina de Cirurgia do Aparelho Digestivo da Faculdade de Medicina da Universidade de São Paulo (FMUSP)2, São Paulo, SPe Faculdade de Medicina de Itajubá1, Itajubá, MG, Brasil.

Endereço para correspondência: Natália Cristina Lima Rodrigues, email: nataliaclr@bol.com.br
Devido seu importante papel para muitas funções homeostásicas e funcionamento de inúmeros tecidos do corpo - particularmente o sistema imunológico -, o uso da glutamina como agente farmacológico em terapia nutricional tem sido abordado intensamente na literatura A sua suplementação tem provado ser benéfica às funções do sistema imunológico, com melhora do balanço nitrogenado e dos parâmetros nutricionais no período pós-operatório e reduz as perdas protéicas nos estado catabólicos graves ${ }^{6}$.

Não existe consenso do efeito da suplementação de glutamina sobre a síntese protéica. No entanto, sugere-se que em animais desnutridos submetidos a trauma orgânico ou não, ela possa ter efeito sobre a taxa de reciclagem protéica. O objetivo deste estudo foi verificar o efeito de dieta suplementada com glutamina sobre variáveis bioquímicas e hematológicas de ratas submetidas a protocolo de desnutrição, induzido por dieta rica em lactose.

\section{MÉTODOS}

O presente trabalho foi aprovado pelo Comitê de Ética da Faculdade de Medina de Itajubá. 
Ratas Wistar fêmeas ( $\mathrm{n}=20)$ e com 21 dias de idade, provenientes do Biotério da Faculdade de Medicina de Itajubá FMIt, foram submetidas ou não à desnutrição calórico-protéica induzida por diarréia, através da administração de dieta rica em lactose $60 \%$ durante 15 dias. Após o período de desnutrição, animais eutróficos ou desnutridos permaneceram durante 30 dias com oferta de diferentes dietas (padrão e experimentais), segundo protocolo padronizado por Tannuri².

A dieta padrão utilizada consistiu em ração comercial para pequenos roedores $\left(\right.$ Purina $\left.^{\circledR}\right)$. Sua constituição básica foi: carbonato de cálcio, farelo de soja, farelo de trigo, alfafa desidratada, fosfato bicálcico, milho integral moído, óleo de soja degomado, cloreto se sódio (sal comum), prémix vitamínico mineral aminoácido, farinha de peixe e aditivo antioxidante.

As dietas experimentais ricas em lactose ou glutamina foram elaboradas a partir da ração comercial utilizada, através da substituição de parte da ração por $60 \%$ de lactose ou $2 \%$ de glutamina, respectivamente.

De acordo com estado e tratamento nutricionais, os animais foram distribuídos aleatoriamente em quatro grupos distintos: 1) GC: animais eutróficos + dieta padrão, 2) GD: animais desnutridos + dieta rica em lactose (60\%), 3) GDGLN: animais desnutridos + dieta rica em glutamina (2\%); e 4) GDP: animais desnutridos + dieta padrão.

Durante os 30 dias de experimento, animais eutróficos e desnutridos permaneceram em gaiolas individuais comuns, sem contato com os outros animais. A oferta de água e das diferentes dietas oferecidas foi feita ad libitum. As ratas eutróficas ou desnutridas dos diferentes grupos foram pesadas nos primeiro, $15^{\circ}$ e $30^{\circ}$ dias.

Ao longo do desenvolvimento do protocolo experimental, as condições ambientais foram monitoradas diariamente, sob ciclo diuturno de luz, ventilação, controle de ruídos e exaustão de odores. Todos os procedimentos experimentais foram desenvolvidos de acordo com as recomendações do Colégio Brasileiro de Experimentação Animal (COBEA)4.

Após o período de suplementação, os animais foram anestesiados com Ketamina (5 unidades/100g) e Xilazina (10 unidades/100g) e submetidos à secção abdominal e punção cardíaca, para coleta de sangue total (aproximadamente $10 \mathrm{~mL}$ ). Metade do volume coletado foi transferida para um tubo heparinizado e a outra metade para um tubo contendo EDTA. Posteriormente, o animal foi sacrificado através de secção do coração.

Após o sacrifício, no Laboratório de Bioquímica da Faculdade de Medicina de Itajubá, o sangue total em heparina foi centrifugado a 2000RPM para obtenção de plasma. As amostras de plasma foram imediatamente congeladas, para posterior análise de variáveis bioquímicas. O sangue total em EDTA foi utilizado para realização de hemograma.

As amostras de sangue em heparina foram submetidas à análise de proteínas totais, albumina e uréia por espectrofotometria (Quimis-Q-108DRD), através do uso de kits específicos $\left(\right.$ Labtest $\left.^{\mathbb{}}\right)$. A contagem da série vermelha foi desenvolvida automaticamente em aparelho específico (Sysmex K-800) e da série branca manualmente, em microscópio (Nikon E-200).

Os dados coletados foram analisados estatisticamente por software Origin 6.0, através do Teste-t Student para amostras pareadas. Considerou-se nível de significância de 5\%.

\section{RESULTADOS}

Apesar do período de desnutrição, os animais que compuseram os diferentes grupos experimentais iniciaram o protocolo de estudo com pesos semelhantes. Porém, nos primeiros 15 dias observou-se menor ganho de peso nos grupos com animais desnutridos, em relação ao controle, independente da suplementação com glutamina. A Tabela 1 mostra a evolução do peso dos animais durante o processo de experimentação.

TABELA 1 - Avaliação dos pesos dos ratos analisados no início e no fim, e o ganho de peso no $15^{\circ}$ e no $30^{\circ}$ durante o experimento

\begin{tabular}{lccc}
\hline & Peso inicial (g) & Peso ganho (g) & Peso ganho (g) \\
\hline & & 15 dias & 30 dias \\
Grupo Controle & $58,0 \pm 7,0$ & $64 \pm 4,24$ & $110.8 \pm 7,8$ \\
Grupo Desnutrido & $61,2 \pm 6,4$ & $46,4 \pm 2,60^{*}$ & $100.4 \pm 4,7^{*}$ \\
Grupo Glutamina & $52,8 \pm 4,0$ & $39,2 \pm 8,9^{*}$ & $92,0 \pm 8,2^{*}$ \\
Grupo Desnutrido Padrão & $47,6 \pm 4,7$ & $33,2 \pm 11,5^{*}$ & $93,6 \pm 9,2^{*}$ \\
\hline
\end{tabular}

Valores em média \pm desvio-padrão* $\mathrm{P}<0,05$ em relação ao Grupo Controle

Em relação às variáveis bioquímicas, observou-se diminuição da uréia no grupo desnutrido com dieta rica em lactose, em relação aos demais grupos, conforme pode ilustra a Figura 1. Não houve diferença estatisticamente significativa na quantidade de proteínas totais e albumina entre os diferentes grupos estudados (Tabela 2 e Figura 2).

TABELA 2 - Parâmetros bioquímicos após 30 dias de experimento

\begin{tabular}{lcc}
\hline & Proteínas totais $(\mathbf{g} / \mathbf{d L})$ & Albumina $(\mathbf{g} / \mathbf{d L})$ \\
\hline GC & $6,92 \pm 0,37$ & $3,14 \pm 0,25$ \\
GD & $6,4 \pm 0,10$ & $2,90 \pm 0,18$ \\
GDP & $6,92 \pm 0,43$ & $2,96 \pm 0,25$ \\
GDGLN & $6,44 \pm 0,41$ & $2,96 \pm 0,15$ \\
\hline
\end{tabular}

Valores expressos em média \pm desvio-padrão. $\mathrm{GC}=$ Grupo Controle; $\mathrm{GD}=$ Grupo Desnutrido; GDRC $=$ Grupo Desnutrido Ração Comum; $\mathrm{GG}=$ Grupo Glutamina

A análise das variáveis hematológicas encontrou diminuição significativa da série branca, notadamente linfócitos e neutrófilos, no grupo desnutrido alimentado com dieta rica em lactose, em relação aos demais grupos estudados (Tabela 3). Não houve diferença nas concentrações de hemácias, hemoglobina e hematócrito em nenhum dos grupos estudados (Tabela 4).

\section{DISCUSSÃO}

No presente estudo, os animais dos grupos desnutridos tiveram menor ganho de peso do que os do grupo controle, independente da suplementação ou não com glutamina. Além de demonstrar a eficiência do modelo de desnutrição com dieta 


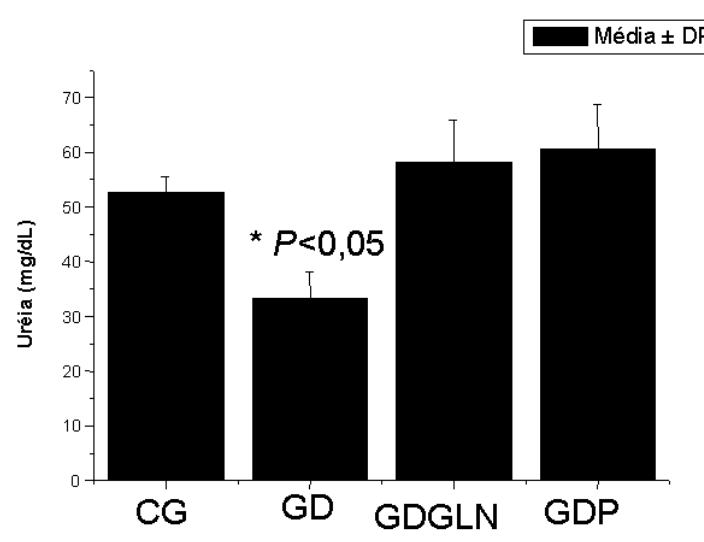

FIGURA 1 - Comparação dos valores plasmáticos de uréia após 30 dias de experimento. $\mathrm{GC}=$ Grupo controle; GD $=$ Grupo Desnutrido; GDGLN = Grupo Glutamina; GDP = Grupo Desnutrido (ração comum)

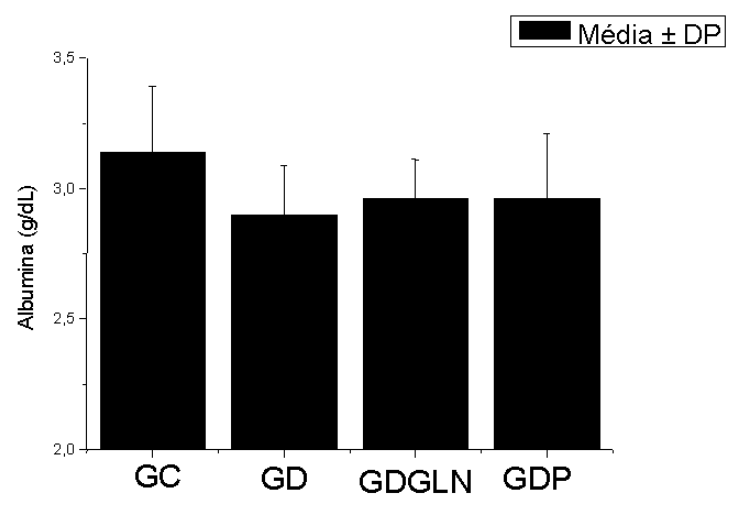

FIGURA 2 - Comparação dos valores plasmáticos de albumina após 30 dias de experimento. $\mathrm{GC}=$ Grupo Controle; GD = Grupo Desnutrido; GDGLN = Grupo Glutamina; GDP = Grupo Desnutrido (ração comum)

TABELA 3 - Valores da dérie branca nas ratas analisadas após 30 dias

\begin{tabular}{lccc}
\hline & Leucócitos totais & Linfócitos & Neutrófilos \\
\hline Grupo Controle & $103 \mathrm{Cel} / \mathrm{mm} 3$ & $103 \mathrm{Cel} / \mathrm{mm} 3$ & $103 \mathrm{Cel} / \mathrm{mm} 3$ \\
Grupo Desnutrido & $7,88 \pm 2,82$ & $6,78 \pm 2,43$ & $0,92 \pm 0,39$ \\
Grupo Desnutrido Padrão & $3,68 \pm 1,03^{*}$ & $3,12 \pm 0,88^{*}$ & $0,47 \pm 0,2^{*}$ \\
Grupo Glutamina & $7,8 \pm 3,0 \#$ & $6,37 \pm 2,37 \#$ & $1,12 \pm 0,63 \#$ \\
\hline
\end{tabular}

*P $<0,05$ em relação a Grupo Controle. \# $\mathrm{P}<0,05$ em relação ao Grupo Desnutrido

TABELA 4 - Valores da série vermelha nas ratas analisadas após 30 dias

\begin{tabular}{lccc}
\hline & Hemácias & Hemoglobina & Hematócrito \\
\hline & $106 \mathrm{Cel} / \mathrm{mm} 3$ & $\mathrm{~g} / \mathrm{dL}$ & $\%$ \\
Grupo Controle & $6,41 \pm 0,25$ & $14,7 \pm 0,51$ & $41,9 \pm 2,09$ \\
Grupo Desnutrido & $6,26 \pm 0,46$ & $14,1 \pm 0,89$ & $40,9 \pm 2,5$ \\
Grupo Desnutrido Padrão & $6,32 \pm 0,47$ & $13,86 \pm 1,05$ & $40,9 \pm 3,78$ \\
Grupo Glutamina & $6,64 \pm 0,42$ & $14.6 \pm 0,76$ & $44,7 \pm 3,12$ \\
\hline
\end{tabular}

$* \mathrm{P}<0,05$ em relação a Grupo Controle. \# $\mathrm{P}<0,05$ em relação ao Grupo Desnutrido rica em lactose, este estudo concorda com o anterior que não encontrou influência da ingestão de glutamina sobre perda ou ganho de peso corpóreo ${ }^{11}$. Considerando-se que a glutamina pode auxiliar no metabolismo protéico, os resultados do presente estudo sugerem que a diminuição da fonte energética foi o principal fator para diminuição do ganho de peso corporal observado.

Contudo, não há consenso sobre a melhora na forma de oferta de glutamina, em relação a ganho de peso, ou seja, ao processo de digestão e sua absorção ${ }^{12}$.

A presença de desnutrição protéica pode ser confirmada por depleções das proteínas estruturais plasmáticas e mudança no seu perfil de aminoácidos ${ }^{9}$. Entretanto, não foram encontradas depleções de proteínas totais e albumina nos animais desnutridos, em relação ao grupo controle. $O$ fato de que a concentração de proteínas totais não diminuiu no GD (grupo desnutrido) em relação aos demais grupos, reforça o fator energético como principal responsável pela desnutrição.

Por outro lado, vale considerar que a albumina apresenta vida média de 12 a 21 dias e mudanças significativas na função renal especifica para sua síntese podem não ser detectadas até esse período, o que a torna um indicador pobre de desnutrição precoce devido a sua vida-média longa ${ }^{7}$. Apenas em estados hipercatabólicos com proteólise ativa a vida média da albumina pode sofrer redução de $50 \%$. O presente modelo de desnutrição não estressada pode ter induzido queda da albumina em longo prazo, sugerindo que o período de estudo foi curto para se detectar deficiências significativas desse aminoácido. Nessas situações, a deficiência de albumina parece ser detectada apenas em desnutrição de terceiro grau ${ }^{10}$.

Se considerar-se a diminuição de uréia no grupo desnutrido tratado com dieta rica em lactose, pode-se sugerir que a deficiência protéica ocorre no modelo de desnutrição adotado. A uréia forma-se principalmente no fígado e constitui o principal produto terminal do metabolismo protéico no ser humano8. Valores diminuídos são encontrados principalmente em situações onde o fígado se encontra afetado ou com oferta protéica restrita ${ }^{8}$.

Estudos descrevem que a desnutrição pode conduzir à imunossupressão ${ }^{13}$. A glutamina é um substrato de glutationa, um dos principais antioxidantes, e ajuda a melhorar a resposta imunológica. Além disso, células do sistema imunológico, assim como os enterócitos, utilizam a glutamina como substrato energético preferencial ${ }^{14,15}$. Os achados deste trabalho confirmam relação entre desnutrição e imunossupressão, já que os animais desnutridos tratados com dieta rica em lactose apresentaram números de leucócitos totais, linfócitos e neutrófilos diminuídos em relação aos demais grupos, e demonstram que a simples re-nutrição do animal é capaz de reverter esse quadro, independente da suplementação com glutamina. Nesse sentido, a glutamina parece não influenciar o número de leucócitos. No entanto, deve-se considerar que o período de estudo analisado pode não ter sido suficiente para que ela influenciasse o número de leucócitos.

O leucograma do grupo aprotéico obteve o menor número de leucócitos, o que foi de encontro com a dieta utilizada; a ausência de proteína afeta o sistema imunológico. Os demais grupos não apresentaram diferença significativa, apesar do 
aumento de leucócitos nos grupos suplementados. Adiferenciação celular mostrou-se compatível com a literatura não sendo observada variações significativas entre os tratamentos ${ }^{16}$.

A desnutrição afeta o sistema imune, particularmente reduz a imunidade, o número de leucócitos e sua função. Estas alterações contribuem para aumentar a suscetibilidade à infecções.

Finalmente, em relação à série vermelha do sangue, os valores médios de hemoglobina encontrados apresentaram valores dentro dos de referência disponíveis na literatura para os animais utilizados no presente estudo ${ }^{17}$. Esses resultados demonstram que o modelo de desnutrição adotado não inerfere na série vermelha.

Os valores de hemoglobina e hematócrito são pouco utilizados como parâmetro nutricional devido à críticas por alterar-se na vigência de perdas ou transfusões sangüíneas e estados de diluição sérica. Embora mais do que 100 g de proteína corpórea estejam sob forma de hemoglobina, sua transformação metabólica é muito lenta e a diminuição ocorre mais tardiamente na depleção protéica ${ }^{18}$.

Novas investigações são necessárias a fim de determinar se a quantidade de glutamina ofertada deve ser maior ou o tempo de experimento mais prolongado.

\section{CONCLUSÃO}

A desnutrição prejudica o número de leucócitos sanguíneos e esse efeito deletério é revertido pela simples renutrição, independente da suplementação com glutamina. A ingestão oral de glutamina não influencia o ganho de peso, incorporação protéica e número de leucócitos de animais desnutridos.

Rodrigues NCL, Nunes LA, Horie LM, Torrinhas R, Waitzberg DL. Glutamine supplementation effect in hematological parameters and nutritional status of rats submitted to malnutrition protocol. ABCD Arq Bras Cir Dig 2007;20(4):270-3

ABSTRACT - Background - Glutamine is the most abundant amino acid in blood stream, playing an important role in the immune system. It is conditionally considered an essential amino acid to certain state conditions such as protein-energy malnutrition. Aim - To verify the effect of glutamine diet supplemented on hematological and biochemical variables in rats subjected to protocol of malnutrition, induced by an enriched lactose diet. Methods - Total of 20 Wistar females rats, 21 days of age, were submitted or not to the protein-calorie malnutrition induced by diarrhea, using an enriched lactose diet $60 \%$ for 15 days. After malnutrition period, eutrophic or malnourished animals remained for 30 days provided with a variety diet (standard and experimental). According to nutritional status and treatment, animals were randomized into four distinct groups: 1) GC: animals eutrophic + standard diet, 2) GD: malnourished animals + enriched lactose diet (60\%), 3) GDGLN: malnourished animals + enriched glutamine diet (2\%); and 4) GDP: malnourished animals + standard diet. After the 30 days of nutritional treatment, blood samples were obtained by cardiac puncture for biochemical (total protein, albumin and urea) and hematological evaluations (red and white blood cells quantification). Results - After 15 days of experimental study, weight gain in the respective groups GD $(46.4 \pm 2.60 \mathrm{~g})$, GDGLN $(39.2 \pm 8.9 \mathrm{~g})$ and GDP (33.2 $\pm 11.5 \mathrm{~g})$ was lower once compared to the control $(64 \pm 4.24 \mathrm{~g}, \mathrm{P}<0.05)$. Biochemical examinations showed a significant difference in the urea dosage in GD as compared to other groups $(33.4 \pm 4.77 \mathrm{mg} / \mathrm{dL}, \mathrm{P}<0.05)$. The leukocytes counting of GD $(3.68 \pm 1.0 \mathrm{cel} / \mathrm{mm} 3 \times 103)$ showed reduced comparing to the rest of the groups $(\mathrm{P}<0.05)$, while red blood cell counting had not presented significant difference. Conclusion - Malnutrition affects leukocytes cell number, although such deleterious counting blood effect can be reversed by simple re-administration of nutrition, regardless of glutamine supplementation. The intake of oral glutamine does not affect the weight gain, biochemical variables of nutritional status, or leukocytes number while malnourished due to enriched lactose diet.

HEADINGS - Supplementation, nutrition. Glutamine. Malnutrition.

\section{REFERÊNCIAS}

1. Borelli Primavera, Blatt Solange L., Rogero Marcelo M., Fock Ricardo A.. Haematological alterations in protein malnutrition. Rev. Bras. Hematol. Hemoter.2004 Mar; 26(1): 49-56.

2. Tannuri Uenis, Carrazza Francisco R., Iriya Kiyoshi. Os efeitos de dieta com suplementação de glutamina sobre a mucosa intestinal do rato desnutrido em crescimento. Rev. Hosp. Clin 2000 Jun; 55(3): 87-92.

3. BILL, Phillips Sports Supplement Review 3rd Issue, Copyright, Golden, 1997.

4. COBEA- Decreto ${ }^{\circ} 24.645$ (1934), estabelece medidas de proteção aos animais, Art. $1^{\circ}$ e Art. $3^{\circ}$, alíneas I, II, IV, V, VI, XX, XXVI e XXVIII. Publicado no Diário Oficial da União, Suplemento ao número 162, de 14.07.1934, Rio de Janeiro

5. Universidade Federal do Rio de janeiro.Rio de Janeiro: Departamento de Bioquímica/Glutamina,1999, atualizado em nov de 1999; Disponível em: http://www.eefd.ufrj.br/deptos/bio/gpcaf/glutamina.htm

6. Vitabrasilnet.com.br.Brasil. Glutamina, atualizado em 29 de out de 2006; Disponivél em: http://www.vitabrasilnet.com.br/glutamina.htm

7. Wikipedia.org. Brasil: Enciclopédia Livre,2006, atualizado em 29 de out de 2006; Disponivél em : http://pt.wikipedia.org/wiki/Ur\%C3\%A9ia.

8. Universidade Federal do Rio Grande do Sul. Rio Grande do Sul: Departamento de Pós Graduação em Bioquimica,2006, atualizado em 16 de out de 2006;. Disponivél em: www.ufrgs.br/bioquimica/posgrad/TMAD/alteracoes_nnp. pdf

9. Maio Regiane, Dichi Bandeira J., Burini Roberto C. Nutritional consequences of macronutrients metabolism impairment in chronic liver disease. Arq. Gastroenterol.2000 Jan ; 37(1): 52-57.

10. Manary M. J., Hart C. A., Whyte M.P. Severe hipophosphatemia in children with washiorkor is associated with increased morta-lity .J Pediatr 1998;133: 789-91.
11. Hill J.O., Fried S.K., Digirolamo M. Effects of fasting and restricted refeeding on utilization of ingested energy in rats. Am. J. Physiol.,247(2):R318R326, 1984.

12. Darmaun D, Humbert B. Does the fate of enterally administered glutamine dependo $\mathrm{n}$ its molecular form? Bound versus free amino acid. Nutrition, 16(1112):1101-1102,2000.

13. Cunha W. D. S.,Frieldler G., Waisberg M., Egami M. I., Costa R. L. F. B. $\mathrm{P}$. Immunosuppression in undernourished rats: the effect of glutamine supplementation. Clinical Nutrition (2003) 22(5): 453-457

14. Grimble R. F. Nutritional modulation of immune function.Nutrition Society (2001), 60, 389.397

15. Seiça T. C. S. S. Nutrientes imunomoduladores: uma perspectiva I. Revista de Saúde Lusitano, n. 3., out-dez, 1996.

16. Santos, Hosana Bandeira; Madruga, Marta Suely; Bion, Francisca Martins; Antunes, Norma Lúcia Marinho; Mendes, Kardilândia; Àguida, Rosa Biochemi$\mathrm{cal}$ and hematological studies in rats involving mineral bioavailability in a diet supplemented with "multimistura". Ciência e Tecnologia de Alimentos, 2004, vol.24, n. 4, ISSN 0101-2061

17. Ringler D, Dabich L. Hematology and Clinical Biochemistry. In: The Laboratory Rat. San Diego: Academic Press; 1979. p.105-19.

18. Fany Govetri SenaI; Eliane Figueiredo TaddeoII; Eduardo Ramos de Andrade NetoII; Márcia do Socorro Rodrigues FerreiraII; Ernani Geraldo RolimII . Nutritional status of patients undergoing treatment in gastroenterology infirmary; Rev. Nutr. vol.12 no.3 Campinas Sept./Dec. 1999

Conflito de interesse: não há Fonte financiadora: não há Recebido para publicação em: 03/082007 Aceito para publicação em: 14/11/2007 